\title{
Participation of children: an alternative to building new cities
}

\author{
L. Brazil dos Santos Argueta \\ Federal Fluminense University, Brazil \\ Genesis - Environmental Education Center, Brazil
}

\begin{abstract}
The present article is based on partial results obtained in the extension project Building Pathways to Sustainability, whose main objective is to create conditions for the participation of children in overcoming the social and environmental problems and build sustainable societies, with reference to the neighborhoods where they reside. The project is a realization of the Pro-Rectory of Extension of the Federal Fluminense University (Rio de Janeiro, Brazil) in partnership with the Genesis - Environmental Education Center (CEAG), with support of Alliance Française of Niterói. In 2009, the project was selected for presentation at UNESCO World Conference on Education for Sustainable Development, in Bonn, Germany. In 2010, the project was among the 100 best practices in Education for Sustainability UNO-HABITAT.

We show how by adopting a methodology based on the components of empowerment of children - from São Gonçalo and Itaboraí - children are overcoming the naturalized view of environmental problems, strengthening selfesteem and organizing small projects and campaigns. Evidently, they are isolated and do not promote structural changes, but they mark the beginning of a process that should extend until they have the skills and information necessary to intervene in the structural causes and thus help build urban spaces with greater equity, social justice, democratic empowerment and sustainability.

Our hope with this report is to contribute to the development of new experience in this area, especially from the university extension. It's necessary to carry out integrated activities of research and extension to create spaces where children together with adults participate in the process of building new cities.

Keywords: sustainable development, education for sustainability, participation of children, democratic empowerment.
\end{abstract}




\section{Introduction}

The guidelines for the construction of sustainable development are systematized in Agenda XXI and can be viewed from two perspectives: an eminently economic one, based on economic agreements as well as certificates, and another one based on the participation of all stakeholders. Both are important: The first because it is related to the production sector and contribute to economic growth, a fundamental aspect of sustainability in construction. The second concerns the presence of all members of society in the process of building sustainability, as this may contribute to the proposals that meet the needs of everyone. The work was developed in the counties of Itaboraí and São Gonçalo, and is based on the second part. The scenery of the action: the urban space, the actors: children aged from 8 to 15 .

The urban area was chosen as a scenario, given that: 1) Brazil has the largest share of its population living in the city, in concentrated form. $60 \%$ of the population live in 224 municipalities with more than 100000 inhabitants, of which 94 belong to urban and metropolitan areas with over 1 million inhabitants. 2) The unsustainability existing in these clusters, especially in its periphery due to a development model that focused on the economic aspect, being implemented only by members of the government sector.

The children were chosen as key players because they suffer more severe impacts of unsustainability. Historically they have been excluded from decision making processes and this exclusion must be overcome. The quotation below is illustrative.

"... consider it necessary to not only know them as distinct social groups, with different cultures and life experiences than those found among the older groups, but mainly listen to them in order to confront together the serious problems that the current Brazilian society poses. Not only are children and young people "at risk", as they say, the whole society is in this situation until we incorporate them in the preparation of projects of today [1].

For us to build sustainable societies in their various dimensions is one of the most important projects today. Such exploration should include the participation of all people, in accordance to Sorrentino:

"In a global perspective, not just admire the look of the Western white man. We need to include women, blacks, young, elderly, children and homosexuals, the southern countries, the interior, the periphery, artists, pacifists and other ethnic minorities, listening to them in their specificity and encouraging to express their dreams, demands and proposals [2].

We share the view of the author that there is no way to overcome the barriers of economics, culturally and ecologically, on global, national, regional or local level, without that all of us participate, including children. Although this idea is shared by many scholars, such as $[1,3-5]$ the question that arises is: how 
feasible is the participation of children? What strategies need to be undertaken? For children living in segregated urban areas, the issue becomes even more delicate because they suffer more discrimination due to where they live, and this often affects self-esteem, which may compromise the ability to participate. How overcome these difficulties?

The construction of answers to these questions has been the object of the Disadvantaged Urban Childhood Program, Environmental Education and Sustainability. Development for seven years in cities that were part of the Metropolitan Region of Rio de Janeiro and includes research, seminars, courses and projects. One very important project is the Building Pathways to Sustainability, whose main objective is to create conditions for the participation of children in overcoming the social and environmental problems and build sustainable societies, with reference to the neighborhoods where they reside. The project is a realization of the Pro-Rectory of Extension of the Federal Fluminense University (Rio de Janeiro, Brazil) in partnership with the Genesis Environmental Education Center (CEAG), and with support from the Alliance Française of Niterói. In 2009, it was selected for presentation at UNESCO World Conference on Education for Sustainable Development, in Bonn, Germany. In 2010, it was among the 100 best practices in Education for Sustainability UNOHABITAT.

The methodology was constructed, with reference to the concept of empowerment, a concept developed within the funding agencies as a way to combat poverty in countries throughout the $80 \mathrm{~s}$. Its background is the construction of a newly proposed development - a sustainable development.

"This concept goes beyond notions of democracy, human rights and participation, to include the possibility of understanding the reality of their environment (social, political, economic, ecological and cultural) reflecting on the factors that shape their environment, as well as taking initiatives to improve their own situation" [6].

It is an awareness of his reality and can be understood as an evolving process of awareness, and foster the growth of understanding about the situation of the subjects experienced, the determinants of the same and the impacts that flow from it, continuing until that individuals are able to intervene in the structural processes that cause this situation. The concept is targeted to the poor segments of the population and in the process of impoverishment, living both in urban and in rural areas, regardless of gender, ethnicity and age, and is based on three components: cognitive, psychological and political, named components Stromquist [7]. To work with children we have adapted the components according to their perspective:

The cognitive component - refers to a consciousness about the reality and causes of domination. For children, this is a dominance of adults, which has as one of the consequences, their exclusion from decision-making processes, whether in private or public aspects. Thus this component must:

a) provide the children with opportunities for discussion on the situation of exclusion that are subjected to at home, school and community life; 
b) provide the understanding by children of the factors that contribute to exclusion;

c) to show children that participation is a right guaranteed in the Convention on the Rights of the Child and the Child and Adolescent;

d) facilitate an understanding of the right to participation, as well as its meanings and benefits;

e) promote knowledge of the History of Children's Rights;

f) to help the child assume the commitment to exercise this right.

The physiological component - refers to the development of self-esteem and confidence, as they, according to [7], constitute requirements for decision making. In the case of residents of segregated spaces, self-esteem is often affected by the "territorial stigma." So consider the need to build, for the children, a picture of your living space without the mediation of negative media and thus strengthen the bonding of their location. [4] shows that exercise participation presupposes the existence of love, which means "to identify with the place and make it yours."

"The knowledge of the city, necessary but not sufficient, makes it possible to love the city, both are essential as a psychological condition to the exercise of citizenship. love the city here means identifying with this place, make it your own, which demand action and involvement of the subject" [4].

The political components - involve the skills and information necessary to conduct the analysis of the social environment in order to produce change. In the case of this study the social environment refers to the residential space located in segregated urban areas. Therefore it is necessary that children can understand the problems in these spaces that have, within the logic of urbanization, spatial segregation and social exclusion. This means that in the framework of the proposed empowerment, they should receive information about the spatial segregation, in general and how it materializes in its city and neighborhood. In addition, there must be places where they can reflect on the impact that segregation does to them, both at present and in the future - and build strategies to overcome this.

This methodology has been used in many studies conducted by me with children in Rio de Janeiro. The political component undergoes some changes in order to work in reality with children. In Itaboraí and São Gonçalo, in addition to spatial segregation, we emphasized the unsustainability in its various dimensions.

In this article we show how the children of São Gonçalo and Itaboraí are overcoming a naturalized view of environmental problems, strengthening selfesteem and organizing small projects and campaigns. Evidently they are isolated actions that don't promote structural changes, but mark the beginning of a process that should extend until they have the skills and information necessary to intervene in the structural causes and to help build urban spaces with greater equity, social justice, democratic empowerment and sustainability. 


\section{In pursuit of sustainable cities}

The development models implemented in Brazil had the marks of the economic focus, the technicality and the inclusion of civil society, whether in planning or implementation. The most obvious result of these models is the conformation of cities with numerous social and environmental problems, which persist even today in various regions of Brazil. The first, in the 50s was based on industrialization, concentrated in only two states of Brazil, São Paulo and Rio de Janeiro. The new centers have received large investments to build infrastructure, related to the reproduction of industrial capital. Although a big population has been directed to these poles, there was concern about investments that ensure the reproduction of workers and their families. This model contributed to the destruction of economic activities in several states, destruction of agriculture and a significant exodus toward the cities, which began to experience problems due to the lack of housing for new residents. At first those residents were living in slums, on the outskirts and then later in lots of cities further away, like São Gonçalo and Itaboraí.

The second model of development began from the 70s and was based in the construction of large projects in cities in different parts of the Brazilian territory. These projects were in the area of energy production so that the conditions of reproduction and expansion of monopoly capital, consisting of state enterprises, multinational companies and domestic companies were guaranteed. The social aspects were relegated, more intensely than in the previous period, resulting in an increase in population of the cities, and misery in the large cities. Of the approximately 33000 inhabitants, 35\% were in cities and 41\% in metropolitan areas. Thus there was a proliferation of "clusters of exclusion". These clusters are composed of some neighborhoods, slums, small and medium-density population and housing, which may be located both in the peripheries, and in central areas of urban centers. Such sites make up a "marginality", which consists of:

"A regime of confinement and socio-spatial exile that emerged in the post-Fordist city as a result of unstable changes in the more advanced capitalist economies and the dismantling of the Welfare State, or its relationship with the segments of the working class and categories dominated by ethnocracy that inhabit the lower regions of the physical and social space" [8].

Throughout the $80 \mathrm{~s}$ and $90 \mathrm{~s}$, locations such as hillsides, riverbanks, roads and surrounding ecosystems, such as mangroves, have been filled by an increasingly impoverished population, constituting what some scholars call the tragedy of the Brazilian urbanization. It manifests itself through different kinds of unsustainability.

During the 90s Brazil has undergone a process of democratization. A significant milestone was the enactment of the new constitution, in which was guaranteed the right to popular participation, through instruments such as councils, unions and classes. The new political scenario in Brazil and the 
emergence of the concept of sustainable development meant new development proposals to incorporate not only the economic dimension but also social, environmental, ecological, cultural, among others.

Such a scenario has caused the creation of courses, research and projects at universities in order to discuss conceptual issues related to sustainable development and strategies for their construction. Participation was considered as one of the tactics being used, but within the radical-democratic perspective. This participation is regarded as the creation of a culture focused on the division of responsibilities in the construction of a collective process and are articulated to citizenship and empowerment. The target horizon is the conception of social transformation so that inequalities can be overcome, as stated [9].

"The radical-democratic conception on participation aims to strengthen civil society and to build paths to a new social reality, without injustice, exclusion, inequality and discrimination" [9].

Its effectiveness can be in any space, and does not have a specific model to be followed and may be exercised by different social actors. It's not an end in itself, but is geared toward the achievement of certain objectives. He makes the assumption that individuals know how to take the necessary actions to the participatory process. This requirement raises the need for training for participation, which according to [10] should cover theoretical information on participation and its object:

"It's necessary that the people or the citizens whom among that participation is encouraged, have enough information available about this area or sector of participation. In addition, there is some theoretical elements to give meaning to participation" [10].

Currently the concept of sustainable development is present in governmental bodies and participation of various sectors of society is ensured. An example is the construction of the petrochemical complex of PETROBRAS - COMPERJ in Itaboraí. The complex will be built on an area of 45 million square feet with an estimated investment of around U.S.\$8.38 billion. The main objective is to increase domestic production of petrochemicals, with the processing of approximately 150 thousand barrels per day of domestic heavy oil and the generation of more than 200000 direct jobs, indirect, and "income effect". The principal industrial enterprise of Brazil, and one of the biggest in the world, COMPERJ marks the resumption of Petrobras to the petrochemical industry and will transform the socio-economic region of influence.

The concern with sustainable development led to the adoption of several measures: One is the creation of CONLEST. This consortium was formed to meet the challenges that the venture COMPERJ will bring to the Eastern Region Fluminense, minimizing the negative consequences and trying to strengthen the positive ones, in a vision of regional cooperation, whose primary objective is to overcome the particular needs of each municipality for the development of public policies aimed at sustainable development throughout the Region and beyond Itaboraí, São Gonçalo, and 11 more counties that constitute CONLEST: 
Niterói, Marica , Tanguá, Rio Bonito, Cachoeiras de Macacu, Guapimirim, Mage, Silva Jardim, Araruama, Casimiro de Abreu. At the international level there is the initiative of UNO-HABITAT to monitor the Millennium goals in the region. The work is done in partnership with three universities and government. There is also the job of monitoring the organization of PETROBRAS Forums in each municipality in order to develop the schedules of COMPERJ XXI. Building of paths to Sustainability is also part of this effort in the pursuit of sustainability and is geared to children.

\section{In pursuit of sustainable cities at the CONLESTE}

The scenario consists of the municipalities of Itaboraí with about 210,000 inhabitants and São Gonçalo with 1,300,000. The social and environmental conditions are poor and are due in large part to the development model implemented in Brazil, especially in the 70s, when they became place of residence of impoverished workers. A brief examination of the various dimensions of sustainability, gives an idea of the local situation and justifies the need for urgent interventions.

a) Environmental sustainability: Refers to the ability to maintain the carrying capacity of ecosystems, which involves the absorption capacity and ecosystem restoration in the face of anthropogenic interference. Local ecosystems are compromised. Most affected are the rivers and the forests. The rivers due to the launch of garbage, sewage and chemical waste, and the occupation of its banks. The woods in the light of fires and use of areas for housing construction.

b) Ecological sustainability - Refers to the physical basis of the growth process and aims to maintain natural capital stocks incorporated into productive activities. The region's natural capital is compromised due to intensive farming that has been occurring for decades.

c) Social sustainability - refers to the living conditions of the population. In both cities the proper conditions are poor, placing the population in a situation of vulnerability, particularly due to the lack or insufficiency of urban services.

d) Political sustainability - Refers to the process of building citizenship in its various angles and aims to ensure the full integration of individuals into the development process. Even with the changes promoted by the new constitution, the incorporation of individuals is still incipient. The population is not yet organized to claim their rights permanently.

e) Economic sustainability - Implies an efficient resource management in general and is characterized by the regular flow of public and private investment. Economic stagnation dominated the region for over 30 years. The installation of COMPERJ inaugurates a new era with countless possibilities of public and private investment. 
590 Sustainable Development and Planning V

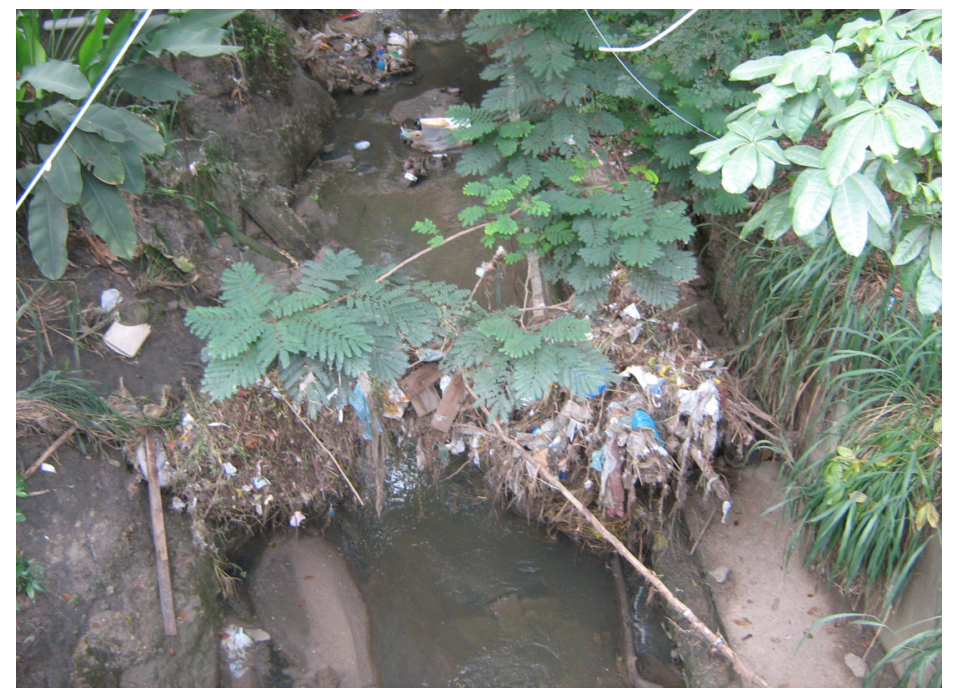

Figure 1: Contamination of watercourses.

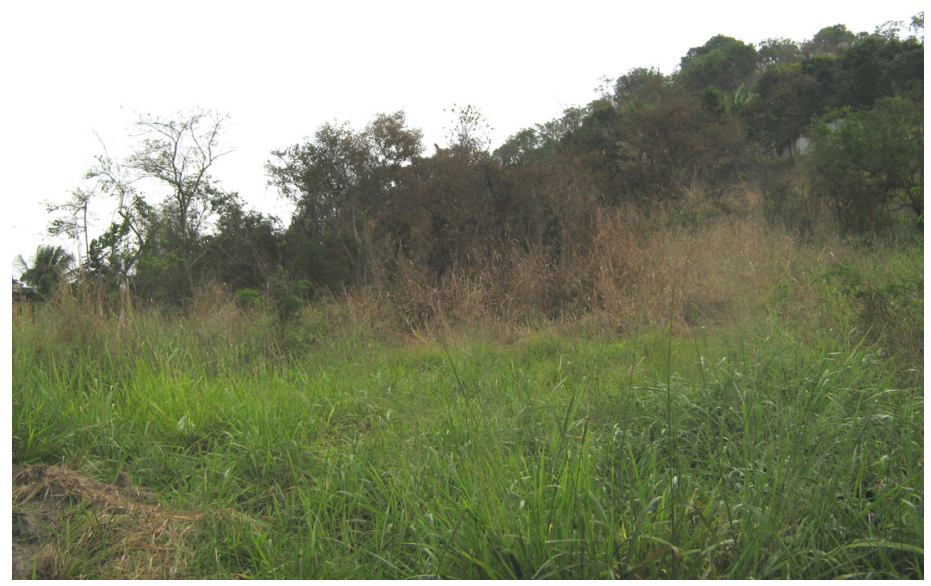

Figure 2: $\quad$ Destruction of vegetation - Itaboraí - São Gonçalo. 


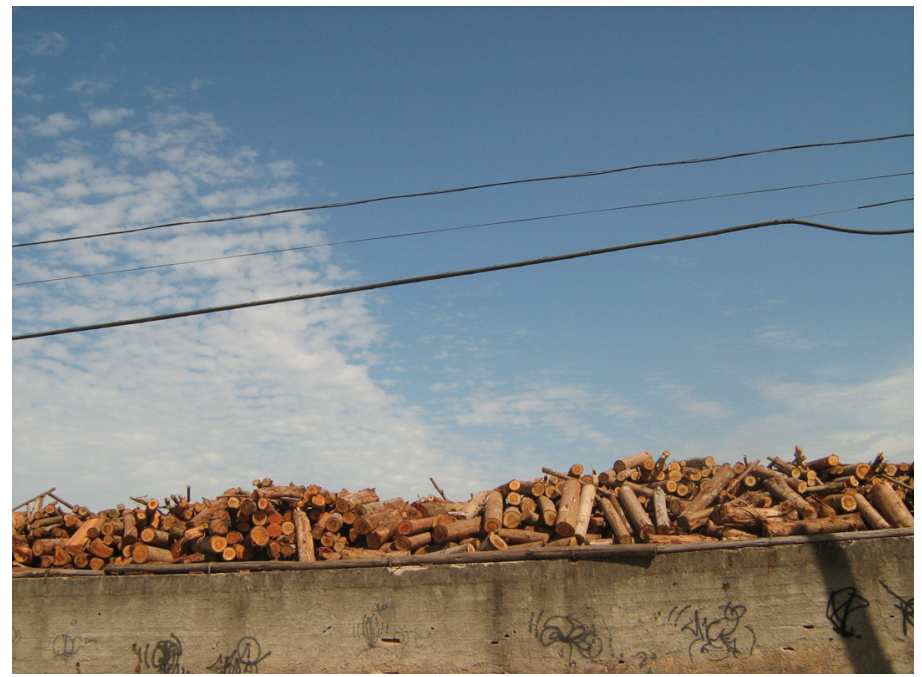

Figure 3: $\quad$ Timber extraction for brick making.

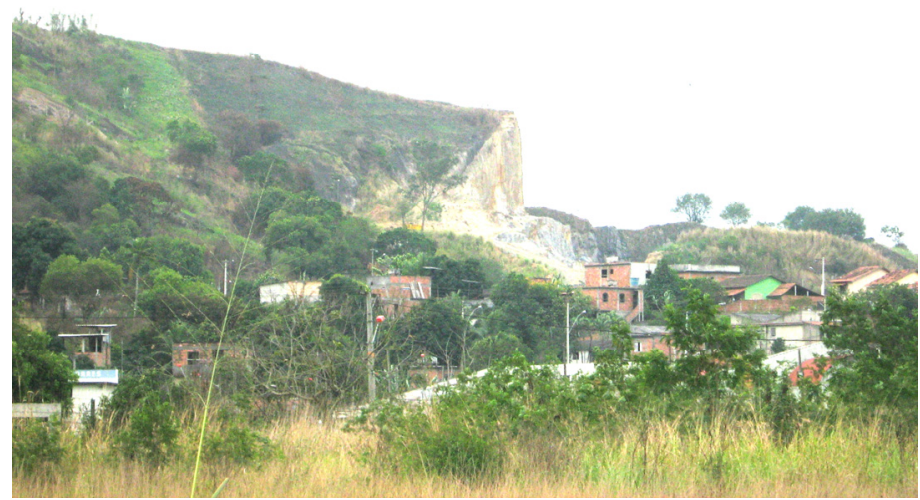

Figure 4: $\quad$ Extraction of stone for construction - Itaboraí - São Gonçalo. 


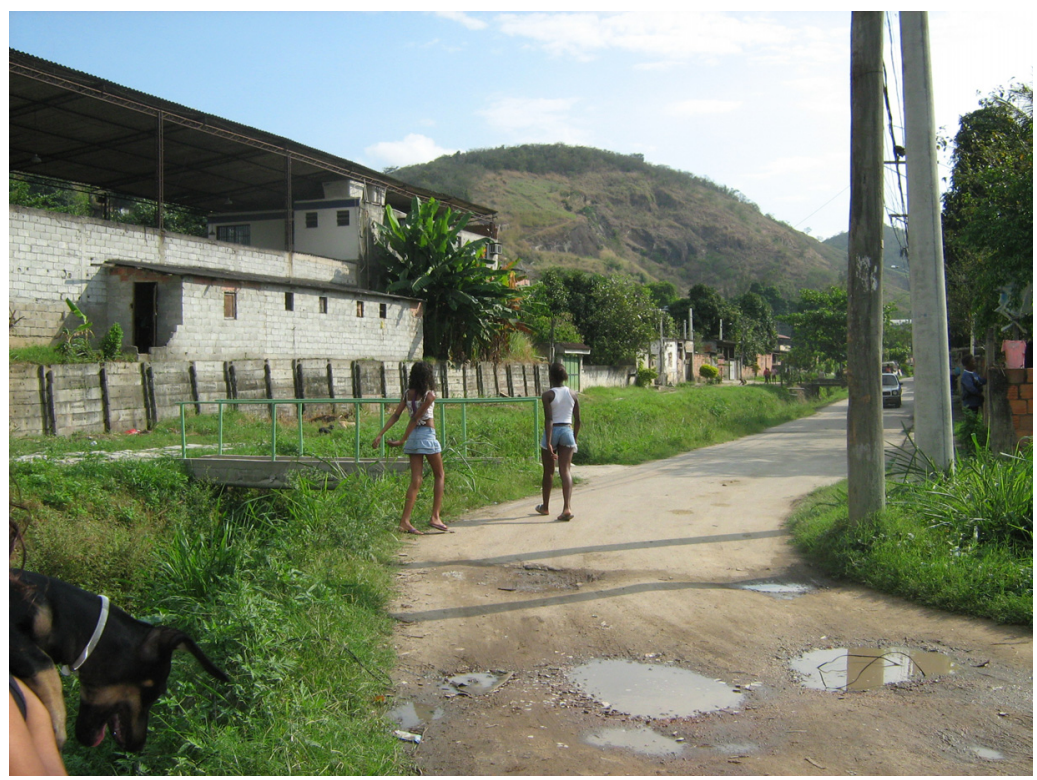

Figure 5: Unpaved streets.

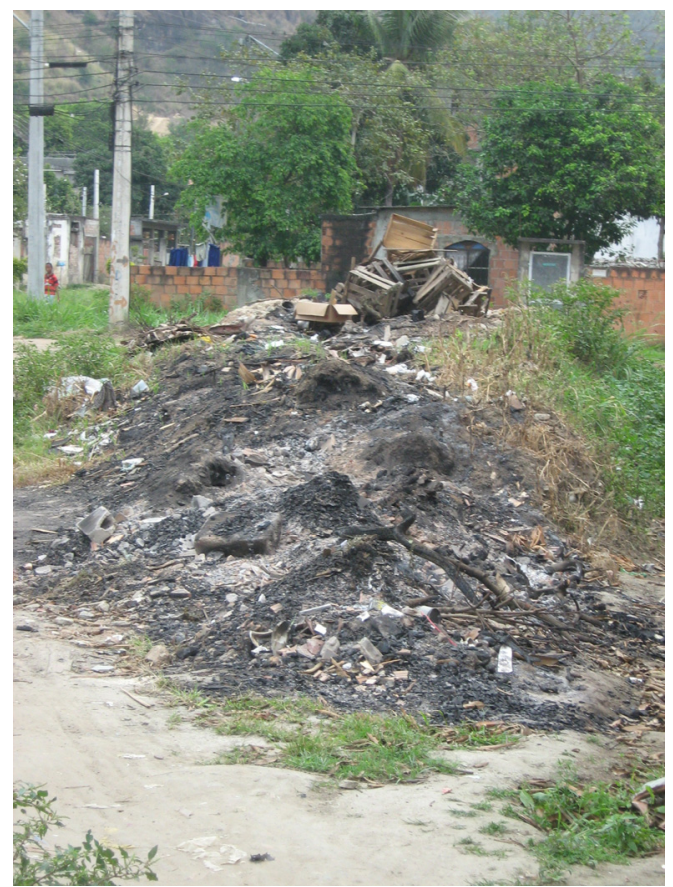

Figure 6: Garbage in the streets. 


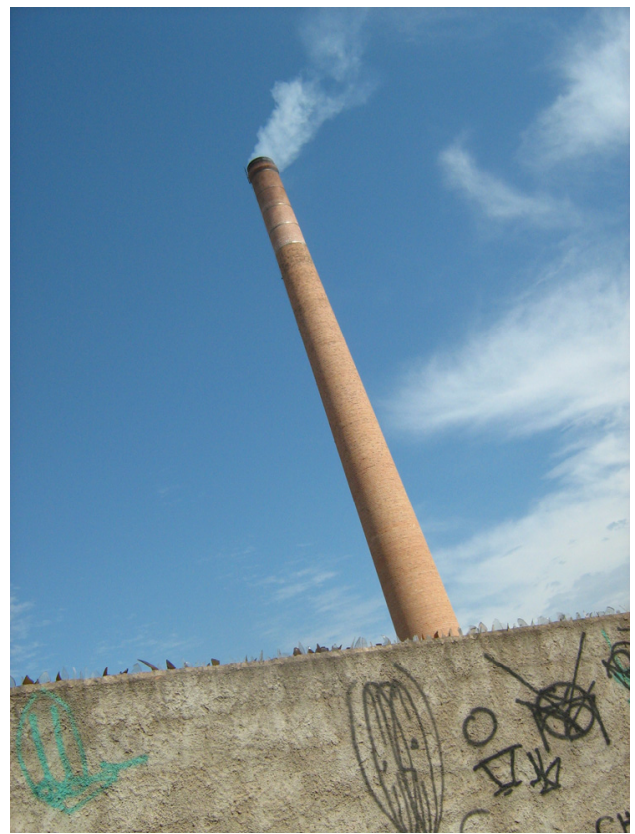

Figure 7: Air pollution.

f) Demographical sustainabiliy - Reveals the limits of carrying capacity of a given territory and its resource base. So far, the region has a great capacity to absorb population. However, it can be compromised with the new developments underway, as it will attract people from various regions of Brazil.

g) Cultural sustainability - Relates to the ability to maintain the diversity of cultures, values and practices of a particular place and that makes up the identity of individuals.

h) Institutional sustainability - Refers to the creation and strengthening of institutional engineering to consider sustainability criteria. This concern is present in the planning of new ventures, especially those related to COMPERJ.

i) Spatial sustainability - Refers to the search for greater equity in interregional relations. The region has some disparities between core and periphery areas. The farther from downtown, more precarious.

j) Technological sustainability - Refers to organized knowledge that is useful for the production of goods and services meeting the demands of society in accordance with environmental sustainability and with the other dimensions.

k) Legal sustainability - Refers to the corpus and the laws that should guide the environmental licensing plans, projects and programs. This bias of sustainability has been widely practiced in the region, especially with members of the Agenda XXI. 


\subsection{Actors}

The project is being conducted with children aged between 8 to 15 years, students of three Integrated Centers for Public Education (CIEP). This kind of school was created in the 80 's - different by offering full-time activities. The project is conducted in one CIEP in Itaboraí and two CIEP in São Gonçalo.

The beginning of the project was in 2009 with the selection of three schools. The choice was due to the location and the interest expressed by management.

Table 1: $\quad$ Actors.

\begin{tabular}{|l|l|l|l|l|}
\hline \multicolumn{1}{|c|}{ CIEP } & Localization & Target audience & Students & $\begin{array}{l}\text { Age } \\
\text { range }\end{array}$ \\
\hline $\begin{array}{l}\text { Pascoal Carlos } \\
\text { Magno }\end{array}$ & $\begin{array}{l}\text { is located in Itaboraí, near } \\
\text { a remaining area of } \\
\text { mangroves and an } \\
\text { extensive area of } \\
\text { vegetation }\end{array}$ & $\begin{array}{l}\text { students of the } \\
\text { second segment of } \\
\text { basic education }\end{array}$ & 1.200 & 12 to 15 \\
\hline Dr Zerbini & $\begin{array}{l}\text { is located in São Gonçalo, } \\
\text { a central area that will } \\
\text { receive new residents due } \\
\text { to the deployment of } \\
\text { COMPERJ }\end{array}$ & $\begin{array}{l}\text { students of the } \\
\text { second segment of } \\
\text { basic education }\end{array}$ & 906 & 12 to 15 \\
\hline $\begin{array}{l}\text { Nicanor } \\
\text { Pereira Nunes }\end{array}$ & $\begin{array}{l}\text { is located in São Gonçalo, } \\
\text { near an area of ecological } \\
\text { interest, the Atlantic forest, } \\
\text { with numerous springs and } \\
\text { that has been destroyed by } \\
\text { deforestation and fires }\end{array}$ & $\begin{array}{l}\text { Elementary } \\
\text { students }\end{array}$ & 551 & 8 to 12 \\
\hline
\end{tabular}

\subsection{Methodology}

The project began with an investigation to identify the perception of children in relation to socio-environmental reality. The techniques used were individual interviews, conversations and interviews recorded on video. The answers given by the children showed that they considered the problems being natural, even the most serious problems such as the lack of garbage collection and sewage treatment, pollution caused by the presence of garbage in the open forest areas and deforestation. At no time were the children shown to be bothered by the situation. For many, the situation is part of urban life. The deforestation is even desirable, because they want a "real town" with tall buildings and cars. Children expressed themselves orally, writing and drawing. For some, the arrival of COMPERJ is the opportunity to have this "true city".

The investigation also showed that the destruction of ecosystems (rivers, wetlands, forests and the Guanabara Bay) was not a worrisome fact for them. How work to overcome the existing problems if for them, this is not a problem? The theoretical support has been given by Boff. He is an author who has discussed in several works, the current framework of environmental degradation. 
Described by him as a civilizational crisis, he blames lack of care as one of the causes of the situation facing millions of human beings and the Earth:

"There is a carelessness and neglect in safeguarding our common home, planet Earth. Soils are poisoned, air is contaminated, waters are polluted, forests are decimated, living species are exterminated" [11].

For the author, to confront and overcome this situation has as one of its pillars the development of care, as well as other values. Care not just for special occasions, but a permanent attitude of care:

Caring is more than an act: it is an attitude. So it covers more than a moment of attention, care and dedication. It represents an attitude of occupation, concern, responsibility and affective involvement with others [11].

In the case of the environmental crisis, it is caring for the planet and its ecosystems and all life that forms part of every day.

Aiming to work aspects of care, an essay contest was held, in which children had to answer the question: Why every day is environment day? To answer this question, they sought information in books, magazines, websites. So they could understand the magnitude of environmental problems that needs constant care.

The denaturalization of the environmental issue has been crafted by a photographic exhibition of the main local environmental problems and the region. The exhibit remained in school for two weeks and each class, along with the teacher, visited and received information from the monitors: an educator and a biologist.

They learned that the situations in their cities are not natural, nor inevitable. We show that they are arising from the way the city is organized: in all cities and towns not much or not at all. We discuss the impacts of insecurity on the lives of children, both at present and in the future. This information helped the children to look at the city in a more critical manner. The approach favoured the impact of greater mobilization.

Two dynamics were held during the exhibition:

a) Party - Each class chose a problem and a small group of children staged a protest in which they were placed against the occurrence of this problem. It is important to note that the situations previously regarded as natural for them, began to be a problem when being the target of protests. The presence of garbage in the streets and the dumping of sewage into rivers had the highest number of protests.

b) Generation of manifestos - The manifesto was drafted by the class, with teacher support. They chose one of the problems, studied the causes thereof, impacts and ways of coping. Then drew up a structured document, which put the group placement. Itaboraí produced a manifesto against the lack of transparency of the environmental policy of the municipality. The document was handed to local authorities for children. In São Gonçalo, the CIEP Dr Zerbini produced several manifestos. One was against a company located near the school and throwing debris in a river. This manifesto was handed to the Campaign for Preserving the water and taking care of rivers. 
The manifestos of the CIEP Nicanor Pereira Nunes were about the destruction of the springs and the release of waste in rivers. They made a documentary in which former residents were interviewed and showed the areas devastated by forest fires and deforestation. They are currently involved with the campaign to raise awareness about the disposition of garbage in inappropriate places in the neighborhood.

This dynamic was very interesting; its implementation has required that children be informed about the legislation and one has used the instrument of Claim. After dynamic and exhibition the children were visiting the areas of ecological interest in the region. The pressure on these areas is very high and they risk being used for housing construction. In São Gonçalo a remnant of Atlantic Forest is being cleared for construction of condominiums and in Itaboraí the remaining areas of mangroves is equally at risk. The visits helped the children understand the importance of the areas in environmental, ecological and economical terms. These initial activities have contributed to them being increasingly more involved in routing local issues. During a demonstration of the people of Itaboraí against the installation of a waste dump in the city, the children produced posters about the importance of natural areas.

After these activities were carried out, the project organized education focusing on the empowerment of children and cognitive components of empowerment, through the following topics:

a) The child and the right to social participation - In this topic the children could reflect on their condition in Brazilian society, the factors that hinder their participation. They received information about the right to participation and its meanings. They had access to the document Child Rights and Housing and above all they were invited to make a commitment to participate.

b) Environment, environmental education and sustainability - in this part, the children could better understand each concept. The issue of sustainability was emphasized, so that they understood the various dimensions of it.

c) Environmental problems: past, present and future - this part was a retrospective of the socio-environmental problems of the region, so that they could understand how they have intensified over time and what the projections for the future are, considering the installation of COMPERJ

d) The COMPERJ in the children's lives - they were given information about the COMPERJ and the implications thereof for the city and region.

e) Strategies for building sustainability.

\section{Conclusion}

The training was essential for the children to organize themselves in the form of a core of environmental education. This is one of the major achievements of the project because it is a space where children can gather to discuss the situation, make proposals and interact with other children. The material produced in the essay contest was organized in the booklet and is being used as support material, both at school and in the core. From the core are working: 
The Center for Itaboraí did the mapping of the internal problems of the school and surroundings. The garbage and deforestation are considered the most serious. To minimize the effects, they started a campaign to encourage the planting of trees. Seeds were distributed and one is currently building a plant nursery on school grounds.

In early 2011, they became part of the group that is drafting the Agenda XXI of the COMPERJ, along with representatives from government, nongovernmental organizations and civil society. The core is a reference in the region in terms of participation.

Children's core CIEP Nicanor Pereira Nunes conducted a mapping of the critical points of the garbage in the neighborhood and started a campaign titled AND YOU DON'T HAVE GARBAGE? They held meetings, studied the topic and set up a strategy with the following steps: Production of materials (brochures and manuals with information), distribution for the neighborhood kids, holding a march and forwarding proposals to the government. Up till now were the first two steps. The march's manifesto and production is planned for the month of April.

Children's core CIEP Dr Zerbini is conducting a campaign of caring for rivers and water conservation. The idea is to sensitize and mobilize the public about the care of the rivers and put pressure on companies to stop throwing wastes into rivers. In April 2010, the river located near the school overflowed, causing deaths and destruction of countless homes. After the creation of the core, a blog for the children was organized and from each school they wrote about their experiences and exchanged information about the work that is being developed in their schools. Additionally, they are available to provide consulting services to children from other schools who want to create centers for environmental education.

Evidently, the overcoming of social and environmental problems arising from a model of development characterized by economic focus, a technological mindset and the non-inclusion of civil society, cannot emerge only through the realization of projects and campaigns. We have to think about changes in this model, because new visions still linger in Brazil.

However we believe that initiatives like this that we present can be important for the creation of new cities, as they mobilize and sensitize the participants regarding the environment and its problems. It can contribute to a better understanding of the nature of existing problems and prepare for interventions. To the extent that the work has continued the children will be able to act on the structural mechanisms that produce unsustainable cities.

Finally, the children of the project are excelling in school and working spaces: churches, scout groups. The most emblematic case is that of the CIEP Pascoal Carlos Magno. This school had occupied the last place in the performance evaluation of state government. After beginning the project the school has jumped to 10. Children participating in the project were rated among the best in the region in 2010. In addition, the text of the compositions produced by them were translated into French and presented at the Alliance Française of 
Niterói, in the celebrations of the International Year of Brazil in France. There is an increased self-esteem and a greater desire to participate.

\section{References}

[1] Dermatin, Zelia Brito Fabri, Faria, Ana Lúcia Goulart, Prado, Patricia Dias. Infancy reserch and oral history. In: Towards a culture of childhood, the research methodologies with children. Campinas: Authors Associates, 1996. - book

[2] SORRENTINO, Marcos; Portugal, Simone; Viezzer, Moema. A educação ambiental de jovens e adultos à luz do Tratado de Educação Ambiental para Sociedades Sustentáveis e Responsabilidade Global. La Piragua - Revista Latinoamericana de educación y política, v.2, p. 93-108, 2009- paper in a journal

[3] Wintersberger, H. Children in modern society: rights, citizenship policies. In: G. Pfeffer and D. Behera (eds) Child and Order Complex. Delhi. p 144-168. - paper in a journal

[4] Castro, Lucia Rabello (org) Subjectivity and citizenship: children, youth and cities. Rio de Janeiro: 7 Letras, 2001 - book

[5] Lansdowne, Gerison. Promoting participation children in democratic decision making, UNICEF, 2001. - Report

[6] Sing, Waresh and Titi, Vangile. Empowerment for development sustainable. Halifax: Publication Ferwood. 1995. - book

[7] Avila Neto, D. Simões. Empowerment: a current issue of equity in the project in Brazil: Brazilian Archives of Psychology, n. 8, out-Dec. 1998 p.14-21. - book

[8] Wacquant, Loic J. D. The Wretched of the city - book

[9] Gohn, Maria da Gloria. Management Councils and sociopolitical participation. Sao Paulo: Cortez, 2001 - book

[10] Ander-EGG, Ezequiel. Participación Ciudadana de la socioedad civil and leadership; Cycles, n.1, 1987 - paper in a journal

[11] Boff, Leonardo. Saber cuidar: ética do humano - compaixão pela terra. Petrópolis. RJ: Vozes.1999. Virtudes para um outro mundo possível. Petrópolis: Vozes, 2005. 3v - book 